\title{
Ethical Theories as Methods of Ethics
}

\author{
Jussi Suikkanen
}

Penultimate draft. Final Draft to be Published in Oxford Studies in Normative Ethics.

\section{Introduction}

The debate about whether traditional ethical theories in normative ethics (consequentialism, contractualism, Kantian ethics, virtue ethics, etc.) should be understood as criteria of rightness or as decision procedures goes back to 1730s. ${ }^{1}$ When these theories are understood as decision procedures, they are taken to provide a sequence of deliberative steps such that, when you are guided by them in reasoning, you make practical decisions as you ought to. In contrast, a criterion of rightness is 'a statement of conditions under which actions are morally right' (ShaferLandau 2010, 130). Such a statement is either neutral about deliberation or it instructs us to follow certain rules of thumb.

Like most ethicists, I used to think that the latter view is more plausible, because ethical theories appear to be bad decision procedures by their own lights: they seem 'selfdefeating' or 'self-effacing'. This is most familiar in the case of consequentialism. Thinking about what options you have, their potential outcomes, how likely those outcomes are, how much value they contain, and then calculating is difficult, burdensome and unlikely to result in a good outcome. $^{2}$

Other theories suffer from similar problems. A virtuous, flourishing agent does not consider the example of an agent who has the character-traits that enable her to be successful in the activities that are characteristic to human beings. Likewise, the requirement to consider what kind of principles could guide a situation, what kind of standpoints

1 See Butler (1736: para. 8). For a list of discussions, see Brink (1989, 216 fn. 4).

2 See Mill (1861, ch. 2, para. 24), Sidgwick (1907, 413 and 489-90), and Parfit (1984, 24-9 and 31-43). 
they create to individuals, and what kind of objections those individuals could make could be reasonably rejected due to how burdensome it would be. And, I doubt that an agent could constitute herself as a practically efficient agent by frequently considering what would happen if everyone adopted her maxims and whether willing such a scenario would lead to contradictions in her will.

I have also had two other reasons to reject the deliberation procedure alternative. Firstly, when students rely on ethical theories in answering difficult ethical questions, the results are invariably awkward. In contrast, when applied ethicists provide compelling arguments for their views on different issues, these arguments rarely rely on ethical theories. If ethical theories were good deliberation procedures, you would expect both (i) that students would get better results by applying them and (ii) that applied ethicists would at least sometimes need to make use of them.

Finally, consider Henry Sidgwick's main argument in The Methods of Ethics (1907). Sidgwick explicitly understood three ethical theories (egoistic hedonism, the commonsense morality of many basic moral duties, and utilitarianism) as methods of ethics - as ways 'by which we determine what individual human beings 'ought' ... to do' (Sidgwick 1907, 1). He then used four tests to determine whether these methods could provide self-evident truths rather than mere opinions. The propositions provided by a method that passed Sidgwick's tests were required to be (i) formulated in clear and precise terms, (ii) stable in careful reflection, (iii) mutually consistent, and (iv) generally agreed upon (Sidgwick 1907, 338-42). Sidgwick then argued that the pluralist common-sense method fails these tests whereas egoistic hedonism and utilitarianism pass them. This led him to endorse dualism of practical reason the idea that there are two equally defensible but conflicting ways to make decisions (Sidgwick 1907, 496507).

I have always found the previous argument problematic. There are, of course, well-known issues with whether Sidgwick chose the right tests for determining whether the methods provide self-evident propositions and with his 
conclusions concerning which methods pass those tests. ${ }^{3}$ Yet, I have always been sceptical about Sidgwick's starting point - the idea that ethical theories should be evaluated as deliberation procedures. More precisely, Sidgwick seemed to draw conclusions about which actions are right (i.e., about the correct criterion of rightness) on the basis of evaluating deliberation procedures, for example, in terms of their ability to garner widespread agreement. This seemed akin to drawing metaphysical conclusions on the basis of epistemic considerations.

I have recently, however, changed my mind: perhaps we should think of ethical theories as something like decision procedures - as methods to be used in moral inquiry. ${ }^{4}$ This chapter describes the line of reasoning that led me to revise my view.

I begin from recent developments in the understanding of consequentialism. §2 outlines how the so-called 'consequentializers' have suggested that consequentialism is a flexible framework in which different first-order ethical views can be formulated as versions of consequentialism. $\S 3$ then suggests that other ethical theories too could be understood as equally flexible frameworks. For reasons of space, it focuses on T.M. Scanlon's (1998) contractualism.

$\S 4$ considers the consequences of the thought that many ethical theories are equally flexible and thus able to capture different first-order ethical views as their versions. It argues that, in this situation, we cannot decide which ethical theory is correct on extensional basis as there will be a version of each theory that is equally extensionally adequate. I then suggest that, as a result, ethical theories should be understood as methods to be used for solving difficult moral problems. I also outline a form of pluralist pragmatism as a guiding principle for theory choice in normative ethics. Different ethical theories can make

\footnotetext{
${ }^{3}$ See Hurka (2014, ch. 7).

${ }_{4}$ Below, I discuss deliberation procedures and methods of ethics interchangeably. Deliberation procedures are sometimes understood as algorithms that are simple to apply, whereas methods are thought of as some less straightforward ways of moral reasoning. In these terms, my thesis is that ethical theories should be understood as methods even if they cannot provide deliberation procedures.
} 
themselves valuable by providing useful ways for thinking about difficult ethical questions, but it need not be that the same ethical theory works best in every case.

\section{The Consequentializing Project}

The flexibility of consequentialism has become evident through the so-called 'consequentializing project'. ${ }^{5}$ I will stipulate that any ethical theory that has the following structure is a version of consequentialism (Suikkanen 2020, $262): 6$

Options: In any situation, there is a set of all the mutually exclusive actions you could do. They constitute your options.

Evaluative: Your options in a choice-situation can be ranked in terms of how good their consequences are.

Deontic: Which actions are right and wrong is a function of the evaluative ranking of your options.

Classical utilitarianism is a version of consequentialism thus understood (see Mill 1861, ch. 2). Its evaluative element states that your options are to be ranked in terms of the total amount of happiness their outcomes contain, and its deontic element stipulates that the option ranked first is right and all others wrong. The resulting version of consequentialism, classical utilitarianism, has many wellknown and often criticized first-order moral implications.

By formulating Evaluative and Deontic differently, we get different versions of consequentialism that disagree with utilitarianism and with each other about which actions are right. The previous consequentialist framework is arguably so flexible that, for any plausible ethical view, a version of consequentialism can be formulated that is extensionally equivalent to it (Dreier 2011, 98).

\footnotetext{
${ }^{5}$ For an overview, see Portmore (2009)

6 See also Dreier $(2011,97)$ and Smith $(2003,576)$.
} 
Firstly, many ethical views claim that certain kinds of actions are right or wrong. We can generate versions of consequentialism that are extensionally equivalent to these views by (i) taking the doings of different kinds of actions to be constitutive consequences of the relevant actions and (ii) by granting that these consequences make outcomes better or worse. ${ }^{7}$ This move, however, is not sufficient to capture all ethical views because some views have more complex structural features. These include (i) agent-centred constraints (cases where you are not permitted to do what has the agent-neutrally best consequences), (ii) agentcentred prerogatives (cases where you are permitted to choose a sub-optimal option), and (iii) moral dilemmas (cases where all options are prohibited).

To accommodate ethical views that contain constraints, the consequentializers have to rely on agent- and time-relative evaluative rankings of options based on their consequences. ${ }^{8}$ So, take a view according to which Ann is not allowed to kill an innocent by-stander even when this would prevent Ben from killing five others. To formulate a version of consequentialism that fits this view, we have to claim that, due to her own agential involvement, the outcome in which Ann kills the innocent by-stander is worse relative to her than the outcome in which Ben kills more people even if from the agent-neutral perspective the latter option is better. This version of consequentialism entails that there are constraints.

To accommodate agent-centred prerogatives the consequentializers can, for example, formulate the deontic element in a 'satisficing' way. ${ }^{9}$ Such satisficing views stipulate that often you are only required to choose a good

\footnotetext{
7 See Dreier (1993, 23 and 2011, 98-99).

${ }^{8}$ See Dreier (1993, 22-23 and 2011, 98-104), Louise (2003), and Portmore (2009, 330-331). For an objection and a response, see Schroeder (2007) and Suikkanen (2009).

9 See, e.g., Slote (1982). For s discussion of this and other ways of consequentializing agent-centred prerogatives, see Suikkanen (2014a).
} 
enough option. In order to determine which options are good enough, these views then either rely on a threshold of how much the value the consequences of permissible options must have or state that the value of the permissible consequences must be 'reasonably close' to the value of the outcome of the best option.

Finally, to accommodate moral dilemmas, the consequentializers can, for example, rely on axiologies that recognize value incomparability. ${ }^{10}$ According to them, in some situations some options have outcomes that cannot be ranked evaluatively (i.e., neither of the outcomes is better than the other nor are they equally good). According to the resulting versions of consequentialism, there will be cases where no action is permissible because there is no option that is better than all other alternatives.

This outline of the consequentializing project suggests that, for every plausible ethical view, there is a version of consequentialism that is extensionally equivalent to it (the debate about whether that actually is the case can continue elsewhere). I, more modestly, only wanted to illustrate how flexible consequentialism is - how the framework allows us to formulate different versions of consequentialism that match different ethical views, even those that have previously been thought to be non-consequentialist.

\section{The Contractualizing Project}

This section outlines how perhaps also other ethical theories are as flexible frameworks as consequentialism. Perhaps, for every plausible first-order ethical view, there are also versions of contractualism, Kantian ethics, virtue ethics, etc. that are extensionally equivalent to it. For reasons of space, I focus on just one theory, contractualism.

Most ethicists associate contractualism with Scanlon's version (Scanlon 1998). Yet, I want to suggest that

\footnotetext{
10 See, e.g., Dreier (2011, 105-107). For a discussion of different ways of consequentializing moral dilemmas, see Suikkanen (2020).
} 
contractualism too should be understood as a flexible framework in which different versions of the theory can be formulated. I take the elements of this framework to be:

Codes: There is a set of all the mutually exclusive moral codes that we could all internalize together. ${ }^{11}$

Normative: The outcomes of the general adoption of the previous codes can be ranked normatively.

Deontic: What actions are right and wrong is determined by which actions the moral code that is normatively ranked first authorizes and forbids.

For the sake of simplicity, I assume that Codes and Deontic are fixed in this general characterisation of contractualism - they remain the same across different versions of contractualism. I will instead focus on the Normative element as the element that allows us to formulate different versions of contractualism (exactly like Evaluative allowed us to formulate different versions of consequentialism).

Let me begin from how Scanlon formulated Normative. For him, the normative ranking of different moral codes is based on reasons, which he argued to be the fundamental normative notion (Scanlon 1998, ch. 1 and 192). On Scanlon's view, the general adoption of different codes affects what kind of lives individuals come to live and thus what kind of standpoints they have (ibid., 203). The burdensome elements of their lives then give the individuals who bear those burdens reasons to object to the moral code under which they live (ibid., 195). The moral code to which individuals have the weakest objections is then the code that cannot be reasonably rejected (and therefore it is ranked first normatively).

Scanlon also provided a first-order picture of what kind of burdensome features of their lives provide individuals with reasons to object to the relevant codes. According to him, these reasons must be generic reasons not based on

11 Given that 'act-contractualism' exists (Sheinman 2011), this element could be formulated more generally. However, for reasons of space, I will focus on views that are based on moral codes, which I understand as different kinds of moral sensitivities rather than as sets of principles (Hooker 2000, §3.5 and Scanlon 1998. 198-9). 
anyone's particular aims, preferences, or tastes and yet they still must be qualities of the person's own life (ibid., 204). Scanlon's examples included bodily harm, not being able to rely on the assurances of others, and not having control over what happens to your body (ibid.). Furthermore, when we read Scanlon, we get a sense from his examples of how strong reasons to object different first-order considerations provide. Scanlon thus relied on a certain implicit first-order theory of reasons to formulate the Normative element of his version of contractualism. This theory determines the normative ranking of the different moral codes in terms of how strong objections individuals can make to them.

Contractualists need not, however, formulate Normative in the same way as Scanlon. Firstly, they could also adopt other first-order views of which considerations count as reasons to object to different codes and how strong objections those reasons ground. Secondly, instead of comparing reasons for objecting to different codes, contractualists could focus, for example, on which moral code everyone has sufficient reason seeing to it that everyone accepts (Parfit 2011, 355). Thirdly, contractualists could also rely on other normative notions than reasons to create the required normative ranking of the moral codes. They could rank those codes, for example, in terms of which code rational individuals would adopt where rationality is understood in either deliberative (Southwood 2010) or decision theoretic terms (Gauthier 1986). By formulating the relevant normative ranking of moral codes in these and other ways, we get different versions of contractualism according to which different actions are right and wrong.

I then suggest that, as a framework in which different versions can be formulated, contractualism is just as flexible as consequentialism. Just as for any plausible ethical view there is a co-extensive version of consequentialism, there will also be a co-extensive version of contractualism. My argument to this conclusion has five parts, but the basic idea is analogical to consequentializing. Just as we get different versions of consequentialism by finessing our axiologies, we get different versions of 
contractualism by finessing our theories of on what grounds different individuals can object to moral codes.

Firstly, to capture ethical views according to which certain types of actions are wrong, the 'contractualizers' have to claim that, when these types of actions are done to a person under a moral code that authorizes those actions, that fact itself provides the victim a sufficient reason to reject the code. So, if an ethical view claims that typing thank-you notes is wrong, the corresponding version of contractualism states that receiving a typed thank-you note is such a burden that it provides a sufficient reason to reject any moral code that authorizes typing thank-you notes.

Secondly, in order to accommodate ethical views that recognize constraints, the contractualizers can stipulate that, when a code requires you to do a certain kind of an action, the fact that you would be doing that action gives you a strong reason to object to that code. So, consider the case of Ann and Ben from $\$ 2$. According to a constraintrecognizing version of contractualism, Ann can object to the codes that would permit or even require her to kill the innocent by-stander on the grounds of how serious burden killing an innocent by-stander herself is. If the contractualizers also stipulate that the previous objection is stronger than any of the five individuals' objections are to the codes that do not permit or even require saving them by killing the innocent by-stander, they have formulated a version of contractualism that entails constraints: cases where you are not allowed to do what has the agentneutrally best consequences. ${ }^{12}$

Thirdly, to capture ethical views that recognize agentcentred prerogatives, the contractualizers can argue that, if you frequently lacked freedom to choose between different permissible options (some of which are sub-optimal), this in itself would count as a burdensome objectionable feature of your life (Scanlon 1998: ch. 6). For example, in this situation your ability to make autonomous decisions would

${ }^{12}$ Scanlon implies that his view is compatible with constraints (Scanlon 1998, 81-6 and 106-7) though see Parfit (2011, 364-5). For a contractualist account of relatively weak deontic restrictions, see Brand-Ballard (2004). For a general discussion of how to contractualize various deontic distinctions, see Kamm (2007, 470-474). 
not be recognized. Because of this, you would have a strong objection to those codes that do not leave you sufficient room to make choices between many different permissible options.

Fourthly, to capture dilemma-containing ethical views, the contractualizers can claim that there are situations in which all codes that authorize an option can be reasonably rejected because there are stronger reasons to object to those codes than to the ones that forbid every option. So, in the Sophie's choice situation, there are first-order theories of reasons according to which Sophie's children have very strong reasons to reject all the codes that would permit any of the options available to Sophie because all these codes fail to respect their dignity as equal moral beings.

The contractualizers can thus formulate different versions of contractualism that can accommodate the rightness and wrongness of different kinds of actions, constraints, prerogatives, and dilemmas. However, they still need to address one more ethical view: classical utilitarianism. This is because contractualist views are often presented as antiutilitarian, as views that rule out utilitarianism as a firstorder ethical view (Scanlon 1998, 234-5). Whilst this is true for many versions of contractualism, the contractualist framework allows us to formulate versions of contractualism that are co-extensive even to classical utilitarianism.

The first alternative is to drop the individualist restriction of Scanlon's contractualism and allow the interpersonal aggregation of different objections to moral codes. ${ }^{13}$ If individuals can pool their reasons to object to different codes and especially if we restrict the content of the aggregated objections to how (un)happy people are, the moral code that maximizes the total amount of happiness becomes the non-rejectable (i.e., the one to which there are the weakest objections). The second alternative is to stipulate that individuals can object to the relevant principles only from an ex ante perspective from which they also know that they are equally likely to come to live as any

${ }^{13}$ See Scanlon (1998, 229-30), Ridge (2001), and Parfit (2003, §2). 
one of the actual individuals. ${ }^{14}$ As John Harsanyi (1975) argued, from this perspective every individual has sufficient reason to object to all principles that do not maximize their own well-being expectation. Thus, if we formulate contractualism in this way, we get a version that is extensionally equivalent to utilitarianism.

If the previous moves are made, then, for any plausible ethical view, there will be both a version of consequentialism and a version of contractualism that is coextensive to it. $^{15}$ Perhaps it could also be shown that Kantian ethics, virtue ethics, etc. are equally flexible. After all, we can create extensionally different Kantian first-order views by formulating in different ways what constitutes a contradiction in universalized willing. Likewise, different views of virtues and human flourishing lead to different first-order virtue ethical views. However, for reasons of space, these possibilities have to be explored elsewhere. For the present purposes, it is enough if both consequentialism and contractualism are flexible frameworks in which different versions can be formulated so that they will correspond extensionally to different first-order ethical views. The rest of this chapter focuses on the consequences of that thought.

\section{Theory Choice in Normative Ethics}

If the traditional ethical theories are flexible frameworks, what consequences does this have for normative ethics and ethical theorizing? In the next sub-section $\$ 4.1$, I first argue that which ethical theory should be accepted can no longer be based on truth or correctness. In $\S 4$.2, I will then consider the prospects of understanding these ethical theories in a new way as methods for doing ethical inquiry and how we should choose which one to use.

\subsection{Truth and Correctness}

The first immediate consequence of the flexibility of consequentialism and contractualism is that it no longer

\footnotetext{
${ }^{14}$ For a defence of ex ante contractualism, see Frick (2015).

15 This means that consequentialists and contractualists are not only climbing one mountain together but rather they can climb every mountain together (Parfit 2011, §64).
} 
makes sense to understand these theories as criteria of rightness. Those theories, as flexible frameworks, are not even in the business of stating under which conditions actions are right and wrong. Rather, only the versions of consequentialism and contractualism that specify the different elements of these frameworks in substantial terms can provide a statement of which actions are supposed to be right. So, at best, only the fully specified versions of the traditional theories could be criteria of rightness.

Relatedly, it equally makes no longer sense to disagree about which of the traditional ethical theories is true or correct. There is a traditional project in moral philosophy in which the defenders of ethical theories argue against one another by presenting counterexamples to their opponents' views, cases in which those views are claimed to have unintuitive ethical consequences. Simultaneously, the defenders of each view try to explain why the alleged counterexamples to their view fail. This project turns out to be pointless.

This is because, on whatever common-sense first-order intuitions the alleged counterexamples are based, we now know that there will be versions of consequentialism and contractualism that match those intuitions. That is guaranteed by the flexibility of those theories as structural frameworks. And, as far as the other traditional ethical theories (Kantian ethics, virtue ethics, etc.) are equally flexible, there will not be counterexamples to those theories either (though if they are not, then the possibility of counterexamples remains).

This means that, if there is a complete set of the first-order ethical verdicts that are objectively true and correct (and I have no reason to doubt that there is), there will also be versions of consequentialism and contractualism that are just as true and correct as that set. After all, those versions, whatever they are like, will be extensionally equivalent to the correct set of moral verdicts. This is why the question of which ethical theory should be accepted cannot be decided on the basis of their truth or correctness.

At this point, I have to address one objection to the previous thesis. Douglas Portmore $(2009, \S 6)$ suggests that, in 
addition to purely extensional claims about which actions are right, traditional ethical theories also make claims about what makes different actions right and wrong. If this is right, then we could evaluate which ethical theory is true, not by focusing on extensional adequateness, but rather by considering how plausible claims the view makes about the relevant right- and wrong-makers. Following Dreier (2011, 112-114), I'll distinguish between two versions of this objections.

Firstly, it could be suggested that ordinary first-order ethical views too make claims about what makes different actions right and wrong (ibid., 112). For example, one view might claim that breaking a promise is wrong because it disrespects the promisee as a person whereas another view might suggest that it is wrong because it disappoints their intentionally created expectations. These two views would be conflicting views even if they agreed that breaking promises is wrong. The question then is: are there versions of consequentialism and contractualism that can capture these theories that are extensionally equivalent but disagree about the right-makers? If there aren't, this could be considered to count against the given framework.

Fortunately, the previous two sub-extensionally different ethical views can be both consequentialized and contractualized. ${ }^{16}$ The consequentialized version of the first view would state that disrespecting the promisee makes promise breaking wrong because it is an intrinsically bad quality of outcomes that lowers the ranking of the options that contain promise-breaking. Likewise, the consequentialized version of the second view would claim that disappointing the relevant expectations makes breaking promises wrong because that, instead of disrespect, makes the promise-breaking containing outcomes rank low evaluatively.

Contractualists can likewise capture the first view by claiming that disrespecting the promisee makes promise breaking wrong because in virtue of that the promisee has a sufficiently strong objection to any principle that permits breaking a promise. Likewise, the second view can be

${ }^{16}$ See Dreier $(2011,112)$ and Väyrynen $(2013,171)$. 
contractualized by stipulating that disappointing the promisee's intentionally created expectations makes promise-breaking wrong because it grounds a sufficiently strong objection to the principles that would authorize breaking a promise. This means that the previous type of sub-extensional differences between ethical views can be both consequentialized and contractualized and therefore they cannot be used to determine which framework is correct either. ${ }^{17}$

There is, however, also a more difficult version of the objection (Portmore 2009, 340; Dreier 2011, 112). It could be argued that consequentialism and contractualism themselves make conflicting claims about what makes actions right and wrong, and therefore only one of the frameworks can be correct. On this construal, consequentialism would state that the fact that an action has the best consequences of the available options is the only right-maker. Likewise, contractualism thus understood would state that actions are always made right by the fact that they are authorized by the non-rejectable code. If the consequentialists and contractualists made these claims, at best only one of these theories would be true.

The reason why we can set aside these versions of consequentialism and contractualism is that they are not plausible. This is well-known from the discussions of the

\footnotetext{
${ }^{17}$ It could be objected that consequentialism and contractualism offer conflicting views of in virtue of what a given first-order consideration is a right- or a wrong-maker of which only one can be true or correct. Yet, here the relevant versions of consequentialism and contractualism would agree on which actions are right and what makes those actions right too and so the 'active' ingredients of the views are the same (Dreier 2011, 113-114). As a result, it could be argued that the disagreement in question is merely a notational one - a verbal one concerning how to represent the same normative reality. More modestly put, it would be at least a disagreement in metaethics concerning what grounds right- and wrong-making relations rather than a disagreement in first-order normative ethics, and it is also a rather difficult question on what grounds such a disagreement could be solved.
} 
so-called redundancy objections to contractualism. ${ }^{18}$ As Judith Jarvis Thomson put it (1990, 30 n. 19):

For my own part, I cannot bring myself to believe that what makes it wrong to torture babies to death for fun (for example) is that doing this 'would be disallowed by any system of rules for the general regulation of behaviour which no one could reasonably reject as a basis of informed, unforced general agreement'.

It is more plausible to think that, here too, the relevant wrong-maker is something first-order and concrete - that the torture hurts the baby or that she will miss out on the things that would have made her life good. And, as we just saw, there are versions of contractualism that can recognize these simple wrong-makers.

The same is true of consequentialism. I similarly cannot bring myself to believe that what makes it wrong to torture babies to death for fun is that doing so fails to maximize the total amount of goodness. Rather, it is again more plausible that the previous first-order considerations are the relevant wrong-makers (which, as we saw, can be recognized as such by the consequentialists).

This means that the second version of the objection fails too. ${ }^{19}$ It's true that there are formulations of consequentialism and contractualism that make these theories put forward conflicting claims about right-makers. These views can be evaluated in terms of truth and correctness, but it turns out that they are highly implausible and thus probably false. And, so, we still have not found a way to evaluate consequentialism and contractualism as flexible frameworks for their truth and falsity. And, as far as I am aware, there is no other plausible way to do so. This is why I want to consider next whether some other principle could guide our theory choice in normative ethics.

\footnotetext{
18 For an overview, see Southwood (2010, ch. 7).

${ }^{19}$ For a different response, see Dreier (2011, 113-4).
} 


\subsection{Methods of Ethics and Pragmatic Pluralism}

Let us then turn to a different alternative. It would be to understand the traditional ethical theories both (i) as flexible frameworks in which different versions can be formulated to match different ethical views and (ii) also as methods of ethical inquiry. Would this be a plausible combination of views?

To explore this question, I will first assume that first-order practical ethical questions can be ordered on a spectrum based on how difficult we think they are to answer. At one end of this spectrum are questions like Thomson's question of whether it is wrong to torture babies to death for fun. Here we are completely certain of the answer: of course, it is! This answer isn't merely based on an intuition but rather it is a carefully considered fundamental moral conviction (that perhaps even counts as substantial knowledge). ${ }^{20} \mathrm{We}$ cannot even imagine what it would be for those actions to be right. ${ }^{21}$ Furthermore, there is also wide agreement about the matter, and our moral conviction is related to what we most fundamentally care about. ${ }^{22}$

At the other end of the spectrum are the moral problems to which we have no answers. These problems often have to do with advances in new biomedical technologies or, say, the development of things like artificial intelligence. They also arise in Sorites series cases (Dunaway 2017, 39-40). Many people are certain that you are not permitted to kill one person to save two others even if you are permitted to do so to save billion people. If you accept these two claims, then there is a range between two and billion where it will be impossible to tell whether it would be permissible to kill one to save that many people. Finally, between the previous ends of the spectrum, there is a whole range of questions where we are more or less certain about the answers.

\footnotetext{
${ }^{20}$ For Rawls's description of carefully considered moral convictions, see Rawls (1951, 181-3). In the wide reflective equilibrium, these convictions are to be checked against empirical knowledge of the origins of our moral intuitions.

${ }^{21}$ See Driver (2008).

${ }^{22}$ Thus, the conviction seems to pass Sidgwick's four tests ( $§ 1$; Sidgwick 1907, 338-42). For the latter point, see Frankfurt (1988) and Korsgaard (2009, ch. 7).
} 
In order to consider whether the traditional ethical theories could be understood as methods to be used in moral inquiry, I begin from the moral problems that we can answer confidently. My proposal is that our carefully considered convictions in these cases constitute 'moral fixed points'.$^{23}$ I have suggested that, for any plausible firstorder ethical view, there is a version of consequentialism and contractualism that is extensionally equivalent to it. In this situation, we should use our carefully considered convictions as fixed points that enable us both (i) to rule out the implausible versions of the previous theories and (ii) to formulate and converge on the more plausible ones. Thus, in these cases, we should not use the traditional ethical theories as deliberation procedures or methods, but rather, the other way around, we should rely on our carefully considered convictions to formulate the acceptable forms of consequentialism and contractualism.

This, of course, means that in these cases the traditional ethical theories do nothing to justify our first-order ethical convictions from any 'Archimedean' independent theoretical perspective (see Hooker 2000, 19-23). Rather, the warrant transfers here wholly from our carefully considered convictions to the acceptable versions of the traditional ethical theories. Despite this, this suggestion has two important advantages.

Firstly, it helps us to explain why we should consequentialize and contractualize in the first place. One reason for this, as Dreier $(2011,116-7)$ has suggested, is that displaying the pattern of our fundamental moral convictions as a version of consequentialism (and contractualism) can help us to represent many general and interesting structural features of our moral sensitivities more clearly.

For example, consider the Transplant case in which a surgeon must decide whether to harvest the organs of a healthy orphan to save five other patients (Thomson 1976, 206). Here most of us are convinced that it would be wrong for the surgeon to do that. Yet, within the consequentialist

${ }^{23}$ See Cuneo \& Shafer-Landau (2014) and especially in this context Rawls (1971, 19-20). 
framework, the versions of consequentialism which can accommodate that conclusion have to recognize something like the distinction of doing and allowing and/or rely on agent-relative evaluative rankings. Similarly, versions of contractualism that fit our convictions in this case have to recognize objections to moral codes that are not merely well-being and death based (as the orphan and the five others would have equal objections on those grounds) (Kamm 2007, 472). They have to claim that the orphan can object, not merely to his own death, but also to how it came about compared to how others would die from natural causes.

These examples show how using our basic convictions to formulate extensionally adequate versions of consequentialism and contractualism can help us to represent interesting structural features of those convictions more clearly. Yet, proceeding from our convictions to acceptable versions of consequentialism and contractualism has also another advantage. It can help us to respond to the key objections to the thought that the traditional ethical theories should be understood as methods or deliberation procedures.

Consider first problem of self-defeatingness. The force of that objection derives from the assumption that, if ethical theories are deliberation procedures or methods, they are to be used as such in every situation, including the ones in which we have full certainty. In the light of this assumption, of course the traditional ethical theories are radically revisionary. They would require us to live our lives in a very different way. We would have to constantly deliberate in a very theoretical, calculative way. It is no surprise that doing so would not make things go well, it would not be what flourishing individuals do, and it would lead to burdens that would be a reason to reject the requirement.

My proposal avoids this problem: it creates no requirement to use ethical theories as deliberation procedures in the cases where we are already certain. In fact, it is hard to see how the flexible frameworks could be used as deliberation procedures in those cases in the first place. This is because these theories do not have any first-order consequences 
before we have formulated their value theories, theories of reasons etc. in substantial terms. And, as I have suggested, the only way to do that is to rely on our antecedent carefully considered moral convictions in the cases of full certainty.

This helps us to avoid the problems of Sidgwick's project too. Sidgwick seemed to draw highly revisionary egoist and utilitarian conclusions about what we are to do even in cases where we already had certainty on the basis of evaluating the three methods of ethics with his four tests. Yet, according to my proposal, in the cases of certainty, our carefully considered moral convictions cannot be overruled by the ethical theories but rather those convictions will help us to formulate the best versions of those theories.

Let us then turn to the moral problems we currently find too difficult. It is here, I believe, we should understand the traditional ethical theories as methods of ethical inquiry, though in a new way. I do not mean that the traditional ethical theories will provide simple step-by-step algorithms that anyone could use to solve these problems. Rather, the flexible frameworks provided by these theories will provide more or less useful ways of thinking about these problems.

In the case of the difficult moral problems, the flexibility of the consequentialist and contractualist frameworks allows us to formulate different versions of the theories that entail different solutions to these problems. In the case of consequentialism, these versions of consequentialism will be formulated around different views of what makes the outcomes of the relevant options good. Likewise, in the case of contractualism, the conflicting versions in these cases will be based on different first-order theories of which features of agents' lives provide them with sufficiently strong reasons to reject different moral codes that could govern the relevant cases.

As a result, when we use the 'consequentialist method' to approach a given difficult moral problem, we have to focus on the question of whether the versions of consequentialism that entail different solutions to the moral problem are based on generally appealing accounts of final value. Likewise, when we use the 'contractualist method', 
we have to focus on the question of whether the relevant versions of contractualism that likewise entail the different solutions are based on generally appealing accounts of firstorder reasons to object to different moral codes. In both cases ultimately, we should be sceptical about the solutions that require gerrymandered and wildly implausible theories of value or reasons for which nothing else can be said except that they provide a certain answer in a particular case (Hooker 2000, 4-8). Likewise, we should consider it an argument for a given solution to a difficult problem if the solution is entailed by a version of consequentialism or contractualism that relies on independently plausible views of value or reasons.

We should, however, notice that using these two methods to approach difficult moral problems guides us to focus on different things and to reason in different ways. Which method should we then use if we assume that there is no 'true' or 'correct' one? Here, I recommend adopting an attitude of pragmatic pluralism. This suggestion has two parts. Firstly, I doubt that we can tell which method we should use from the arm-chair a priori and before any actual moral inquiry. Rather, we should try to solve different difficult ethical problems by relying on the previous methods and see what works. ${ }^{24}$ Perhaps it will turn out that better arguments for different solutions to the difficult problems can be provided by relying on either the consequentialist or the contractualist framework.

However, it might also well be that some problems are better approached through different versions of consequentialism whereas others through different versions of contractualism (or Kantian ethics or virtue ethics etc.). Let me illustrate this idea. When it comes to climate change, there are extremely difficult ethical questions of exactly which climate change policies we should adopt. These questions are usually approached

${ }^{24}$ By a method that 'works', I mean one that can be used for making progress in the relevant debate. By progress, I do not mean everyone converging on truth on the whole question, but more modestly the method being able to provide clarity on the question, and to help us to critically evaluate smaller arguments in the domain, to tell us what kind of considerations are relevant and how, what kind of distinctions we ought to rely on, and so on (Chalmers 2015). 
within the framework of expected value consequentialism. Yet, the ethicists and economists who come to conflicting conclusions concerning different climate change policies rely on different versions of consequentialism based on different axiological assumptions. ${ }^{25}$ These assumptions are different views of risk and uncertainty, the rate at which future goods should be discounted, and about whether only human well-being has intrinsic value or whether other goods such as biodiversity have intrinsic value too. And, the ethical debates about these issues seem to provide constructive ways for approaching the climate change policies within the consequentialist framework. ${ }^{26}$

In contrast, it is not clear whether we could make equal progress in approaching the large-scale ethical questions concerning different climate change policies through the contractualist, Kantian and virtue ethical frameworks. One reason for this is the different policies affect billions of people and whole biosystems in so many complex ways (and there is also so much uncertainty) that is not clear how all these considerations could even be taken into account in the other ethical frameworks. Perhaps for this reason, majority of the work in climate change ethics continues to be done in the consequentialist framework and there are few compelling contractualist (or Kantian or virtue ethical, or ...) discussions of the central ethical problems in this domain. ${ }^{27}$

The fact that the consequentialist framework is the most useful approach to climate change policies does not, however, entail (i) that contractualism would be 'false' in any way, nor (ii) that the consequentialist framework provides the best method for approaching all difficult moral problems. Firstly, with (i), even if we have to rely on the consequentialist method in answering the previous questions, we know that there will also be versions of

\footnotetext{
${ }^{25}$ See Broome (2012, chs. 6 - 10, and especially 97-103).

${ }^{26}$ See, e.g., the essays in Walsh, Hormio and Purves (2016).

27 There are, of course, some such discussions. For my own contractualist discussion, see Suikkanen (2014b) and for a human rights-based take, see Caney (2010). Yet, it is difficult to see how such accounts could answer the difficult ethical questions concerning exactly which climate change policies we should adopt.
} 
contractualism that correspond to those solutions. This is guaranteed by the 'contractualizing project' outlined in $\S 3$.

Secondly, a method that works best in one case need not do so elsewhere. For example, one domain of ethical problems in which I find the contractualist framework more helpful than the consequentialist one is promise-keeping (see Scanlon 1998, ch. 7). There are many promises of which we are certain that they ought to be kept and many others that we know we shouldn't keep, but there are also many cases in which it is difficult to tell whether we ought to keep a given promise. These include cases where it is uncertain whether a valid promise has been made and cases where keeping the promise turns out to be either very demanding or conflict with one's other moral duties. In these cases, it seems more useful to consider what kind of consequences different options have to the particular individuals involved and what kind of objections they could make to different alternatives on the basis of those consequences. Here, there are only few individuals involved, the consequences to each individual are not complex, they take place immediately, and there isn't much uncertainty involved either. Here the consequentialist framework seems to add unnecessary complexity whereas the contractualist framework enables us to focus on the relevant factors.

Yet, this too does not make contractualism the 'correct' framework. This is because, to whatever solutions to the difficult promise-keeping cases we are led via the contractualist reasoning, it will be possible to formulate versions of consequentialism that fit those conclusions. This is again guaranteed by the flexibility of the consequentialist framework. Likewise, the fact that the contractualist method is helpful in the promise-keeping case does not make it any better elsewhere (such as in the climate change one).

I want to make one final observation about these cases and the idea of using moral theories as methods to solve them. In $\S 1$, I noted that students tend to use ethical theories poorly as methods whereas applied ethicists who actually make progress rarely rely on them. The proposal outlined here, fortunately, seems compatible with that observation. 
Firstly, students often fail to apply the ethical theories in the right way. Rather than taking them to be flexible frameworks in which different versions can be formulated and compared, students take just one, usually the most basic version of the theory and apply that version to solve the ethical problem that interests them. This overlooks the fact that there are different, more sophisticated versions of the given theory that provide different solutions to that problem. The problem is that students rarely attempt to compare the merits of these versions.

What about the professional ethicists? Admittedly few of them explicitly frame their investigations of the first-order ethical problems in terms of comparing different versions of consequentialism or contractualism. In this respect, the outlined methods might still seem untested. It would thus be interesting to see whether progress in applied ethics could be made by formulating different discussions explicitly in the ways suggested above. I can only hope that this would have good consequences.

I suspect, however, that many applied ethicists would reject my suggestion because it only adds unnecessary complexity to their otherwise fine work. This might well be true, but I don't think it conflicts with the suggestion I have made. This is because it could be argued that much of the work in applied ethics already in some implicit form relies on the consequentialist and contractualist methods even if the relevant discussions are not formulated explicitly as comparisons of different versions of consequentialism or contractualism. After all, when applied ethicists, for example, consider whether some new biomedical technology should be made available, at least in some form they tend to consider the potential good and bad consequences of those technologies and what kind of objections different people could make to their introduction on the basis of how the technologies would affect them. This is why many applied ethicists seem to already be applying the consequentialist and contractualist methods 
in some intuitive, implicit way even if this is not made explicit for the reader. ${ }^{28}$

As a result, I hope that my proposal can avoid the concern that it is to revisionary in terms of what applied ethicists actually do. Finally, one more question remains to be addressed: What about the third type of moral problems which we can answer more or less confidently? My suggestion is that, in these cases, we should understand the outlined methods of ethics in the light one of the central elements of Rawls's notion of reflective equilibrium - the idea that 'we work from both ends' (Rawls 1971, 20). When it comes to the moral questions we can answer with relative confidence, we usually can use our convictions to converge on the most plausible versions of consequentialism and contractualism. Those versions will, again, only provide clearer structural representations of our convictions but they do little to justify them..$^{29}$ Because of this, in ordinary life, there isn't often a need to rely on the traditional ethical theories as deliberation procedures.

Yet, in some cases in which our moral convictions are both less certain and also represented to us as substantial versions of consequentialism or contractualism, we may be surprised by how problematic theories of value or reasons are required to formulate those versions of consequentialism and contractualism. In these situations, we can also come to recognize that the other versions of consequentialism and contractualism that match the solutions we were originally inclined to reject can be formulated by relying on more plausible theories of value and reasons. When this happens, the process of comparing the relevant versions of the ethical theories and how

\footnotetext{
${ }^{28}$ Let me give two illustrations of this. Firstly, the questions of ideal population size in population ethics are standardly approached through comparing different theories of value in the consequentialist framework (see Greaves 2017). Secondly, even Thomson's (1971) famous defence of abortion and many critical discussions of it could be read as evaluations of different views of which personal burdens ground sufficient objections to different principles governing abortion. ${ }^{29}$ However, sometimes if the relevant versions of consequentialism and contractualism are based on independently plausible general accounts of value and reasons we can gain new, additional justification for our first-order convictions in these cases too.
} 
compelling their elements are can lead us to change our moral convictions. In these cases, we thus work from the more plausible versions of the relevant theories to improved moral convictions. This means that, as methods, the traditional ethical theories can also sometimes lead to new ethical discoveries and the rejection of our former firstorder moral views.

\section{Conclusion}

The orthodox view is to think of ethical theories as criteria of rightness - as statements of the conditions in which actions are right and wrong. Against this orthodoxy, I have outlined a new argument for the view that the traditional ethical theories would be better understood as methods to be used in moral inquiry - as a type of deliberation procedures. This argument is based on the idea that the traditional ethical theories are flexible frameworks in which different ethical views can be formulated as versions of those theories. It may well even be that, for any plausible ethical view, there are at least versions of consequentialism and contractualism that are extensionally equivalent to it.

I then argued that, in this situation, the flexible frameworks provided by the traditional ethical theories cannot be understood as criteria of rightness (whereas their versions can be understood in that way). I suggested that, as a result, these frameworks should be understood as methods - as different ways for approaching and solving difficult ethical problems. These methods allow us to think about such problems through comparing different versions of the theories based on different views of value and reasons. Through evaluating these underlying assumptions about value and reasons, we should be able to make new progress with difficult first-order ethical questions. I also suggested that perhaps different ethical problems are best approached through the frameworks provided by different ethical theories. 


\section{Bibliography}

Brand-Ballard, J. (2004): 'Contractualism and Deontic Restrictions'. Ethics 114: 269-300.

Brink, D. (1989): Moral Realism and the Foundations of Ethics. Cambridge, Cambridge University Press.

Butler, J. (1736): A Dissertation upon the Nature of Virtue, reprinted in S. Darwall (ed.): Five Sermons. Indianapolis, IN, Hackett, 1983.

Caney, S. (2010): 'Climate Change, Human Rights, and Moral Thresholds'. In S. Humphreys (ed.): Human Rights and Climate Change, Cambridge, Cambridge University Press, 69-90.

Chalmers, D. (2015): 'Why Isn't There More Progress in Philosophy?'. Philosophy 90: 3-31.

Cuneo, T. \& Shafer-Landau, R. (2014): 'The Moral Fixed Points: New Directions for Moral Nonnaturalism'. Philosophical Studies 171: 399-443.

Dreier, J. (1993): 'Structures of Normative Theories'. The Monist 76: 22-40.

Dreier, J. (2011): 'In Defence of Consequentializing'. Oxford Studies in Normative Ethics 1, 97-119.

Driver, J. (2008): 'Imaginative Resistance and Psychological Necessity'. Social Philosophy and Policy 25: 301-13.

Dunaway, B. (2017): 'Ethical Vagueness and Practical Reasoning'. The Philosophical Quarterly 67: 38-60.

Frankfurt, H. (1988): 'Identification and Wholeheartedness', in his The Importance of What We Care about: Philosophical Essays, Cambridge, Cambridge University Press, 159-77.

Frick, J. (2015): 'Contractualism and Social Risk'. Philosophy and Public Affairs 43: 175-223.

Gauthier, D. (1986): Morals by Agreement. Oxford, Clarendon Press.

Greaves, H. (2017): 'Population Axiology'. Philosophy Compass 12: 1-15.

Harsanyi, J. (1975): 'Can the Maximin Principle Serve as a Basis for Morality? A Critique of John Rawls's Theory'. The American Political Science Review 69: 594-606. 
Hooker, B. (2000): Ideal Code, Real World. Oxford, Oxford University Press.

Kamm, F. (2007): Intricate Ethics. Oxford, Oxford University Press.

Korsgaard, C. (2009): Self-Constitution. Oxford, Oxford University Press.

Louise, J. (2004): 'Relativity of Value and the Consequentialist Umbrella'. The Philosophical Quarterly 54: 518-36.

Mill, J.S. (1861): Utilitarianism.

Parfit, D. (1984): Reasons and Persons. Oxford, Oxford University Press.

Parfit, D. (2003): 'Justifiability to Each Person'. Ratio 16: 368-90.

Parfit, D. (2011): On What Matters, vol. 1. Oxford, Oxford University Press.

Portmore, D. (2009): 'Consequentializing'. Philosophy Compass 4: 329-47.

Rawls, J. (1951): 'Outline for a Decision Procedure for Ethics'. The Philosophical Review 60: 177-92.

Ridge, M. (2001): 'Saving Scanlon: Contractualism and Agent-Relativity'. The Journal of Political Philosophy 9: 472-81.

Scanlon, T.M. (1998): What We Owe to Each Other. Cambridge, MA, Harvard University Press.

Schroeder, M. (2007): 'Teleology, Agent-Relative Value, and the "Good"'. Ethics 117: 265-95.

Shafer-Landau, R. (2010): The Fundamentals of Ethics. Oxford, Oxford University Press.

Sheinman, H. (2011): 'Act and Principle Contractualism'. Utilitas 23: 288-315.

Sidgwick, H. (1907): The Methods of Ethics, $7^{\text {th }}$ ed. London, MacMillan.

Slote, M. (1982): 'Satisficing Consequentialism'. Satisficing Consequentialism'. Proceedings of the Aristotelian Society, Suppl. 58: 139-64.

Smith, M. (2003): 'Neutral and Relative Value after Moore'. Ethics 113: 576-98.

Southwood, N. (2010): Contractualism and the Foundations of Morality. Oxford, Oxford University Press.

Suikkanen, J. (2009): 'Consequentialism, Constraints and the Good-Relative-to: a Reply to Mark Schroeder'. Journal of Ethics \& Social Philosophy 3: 1-9. 
Suikkanen, J. (2014a): 'Consequentialist Options'. Utilitas 26: 276-302.

Suikkanen, J. (2014b). 'Contractualism and Climate Change'. In M. di Paola and G. Pellegrino (eds.): Canned Heat: Ethics and Politics of Climate Change, London: Routledge, 115-28.

Suikkanen, J. (2020): 'Consequentializing Moral Dilemmas'. Journal of Moral Philosophy 17: 261-289.

Thomson, J.J. (1971): 'A Defence of Abortion'. Philosophy and Public Affairs 1: 47-66.

Thomson, J.J. (1976): 'Killing, Letting Die and the Trolley Problem. The Monist 59: 204-17.

Thomson, J.J. (1990): The Realm of Rights. Cambridge, MA, Harvard University Press.

Väyrynen, P. (2013): 'Grounding and Normative Explanation'. Proceedings of the Aristotelian Society, suppl. 87: 155 - 78.

Walsh, A., Hormio, S. \& Purves, D. (eds.) (2016): The Ethical Underpinnings of Climate Economics. London: Routledge. 